\title{
A multifaceted approach to improving motor vehicle restraint compliance
}

\author{
Marcus J Hanfling, Lorna G Mangus, Anne C Gill, Rick Bailey
}

\begin{abstract}
Objectives-To increase proper use of seat belts and car seats, thereby reducing morbidity and mortality from motor vehicle collisions.

Setting-The Vehicle Injury Prevention program community intervention was implemented in Houston, Texas. Effectiveness data are limited to "target area one", an impoverished neighborhood in northeast Harris County.

Methods-This multifaceted public health education campaign brought together six segments of the community: education, health, government, law enforcement, private industry, and the media, to improve restraint use. It was evaluated by observation of proper restraint use before and nine months after implementation. Trained, independent observers made observations of occupants in the target area and at two comparison sites. Pre-post differences in restraint compliance were calculated by a standard binomial proportion test.

Results-Motorists in target area one significantly improved their restraint use by $15 \%(p<0.05)$ from $39 \%$ pre-intervention to $54 \%$ post-intervention, whereas use in the comparison neighborhoods remained unchanged.

Conclusions-Implementation of a public health education program, combined with economic incentives to increase vehicle restraint use, can be successful with multifaceted community support.

(Injury Prevention 2000;6:125-129)
\end{abstract}

Keywords: vehicle restraint use; community intervention

Approximately 300000 persons die and 10-15 million are injured each year in traffic crashes throughout the world. ${ }^{1}$ According to the National Highway Traffic Safety Administration (NHTSA) analyses, death and disability could be reduced more than $50 \%$ with the use of safety restraints. ${ }^{2}$ However, in 1996, more than $60 \%$ of the occupants killed were unrestrained. $^{3}$

Road traffic accidents can produce an enormous drain on health services. Saudi Arabia's dramatic increase in acute health care facilities in the last 15 to 20 years parallels that of a rise in the number of motor vehicles and subsequent road traffic accidents. ${ }^{4}$ Saudi Arabia now spends more per capita on health care than any other country in the world. Besides the increased emergency medical services necessary to treat trauma victims, there is also a need for rehabilitative health services to treat long term disability from the injury.

Mandatory child restraint and seat belt laws have increased seat belt and car seat use throughout the world. Australia has reduced its road traffic fatalities by $49 \%$ since introducing its safety belt legislation in $1970 .{ }^{5}$ In the United Kingdom, legislation that made front seat occupant restraint use compulsory was associated with a fall in the death rate of these passengers of 400 per annum, ${ }^{6}$ but $80 \%$ of children who were killed or seriously injured were travelling in the rear seat. ${ }^{7}$ Most were not wearing seat belts. In Hungary in 1993, the crude mortality rate for motor vehicle crashes decreased $9 \%$ in the month after the safety belt use law was expanded from driver and front seat passengers to include rear seat passengers. ${ }^{8}$ Observational surveys conducted in Fife, Scotland, before and after legislation was expanded in 1991 to include rear seat passengers, showed that rear seat restraint use increased by $77 \%{ }^{9}$

In the National Occupant Protection Use Survey, conducted at a random sample of sites across the United States, only $61 \%$ of children under 5 years old were found to use child safety seats and seat belts. ${ }^{10}$ In addition, certain risk factors - that is, age, gender, minority raceand parents with less than a high school education, were associated with lower use rates. ${ }^{10}{ }^{11}$

Aiming to reduce morbidity and mortality resulting from childhood motor vehicle injuries, Baylor College of Medicine's Pediatric Injury Center developed the Vehicle Injury Prevention (VIP) program. It was modeled after North Carolina's Click It or Ticket program, a successful, statewide public education campaign combining high visibility enforcement of its safety belt law and an economic incentive. ${ }^{12}$ Five years after the inception of Click it or Ticket, North Carolina's restraint use rate increased from $64 \%$ to $84 \%$.

The VIP program combined a number of community intervention strategies, including a multifaceted approach with public-private partnerships, public awareness, education, and an economic incentive package. This report focuses on the effect of the VIP program on the first area targeted to receive the intervention in Houston, northeast Harris County, a community at high risk. The objective was to increase proper use of restraints.

\section{Methods}

STUDY POPULATION

Houston is a large multiethnic community of 1.5 million. In the target area, a high proportion $(76 \%)$ of the residents are impoverished African-Americans. ${ }^{13}$ More than 60\%
TX 77030, USA

(e-mail: MarcusHanfling@

hchd.tmc.edu) 
had less than 12 years of education, and in 1990 , the median income was $\$ 9117$. Implementation of the VIP program in this area was supported enthusiastically by community leaders, political figures, church leaders, and corporate sponsors. The public elementary schools that served as control schools were selected because they were outside the target area.

PROGRAM IMPLEMENTATION

The VIP program established partnerships between six segments of the community: health care, education, law enforcement, private industry, government, and the media. The intervention in the target area included safety education in three public elementary schools and two community health centers, as well as an economic incentive package administered by the Houston Police Department and paid for by the greater Houston business community. Media involvement was not limited to the target area and the safety education provided as part of prenatal and parenting classes at district hospitals and community health centers was also aimed at the larger community.

\section{(1) Health care}

An education component was implemented at the two county hospitals and at all county health clinics. Materials distributed included brochures and VIP $\mathrm{T}$ shirts. Other safety videos and literature were available upon request. Harris County Hospital District employees integrated VIP material into the patients' usual health care visits, particularly in the newborn, prenatal, and parenting clinics.

\section{(2) Education}

Elementary school principals identified school nurses or social workers to become trained to incorporate this program into existing safety educational/awareness programs.

Each safety educator went through a two part training program: part I taught the fundamentals of automobile safety, including the correct installation of a car seat; part II was conducted by BrainLink, a project of Baylor's Department of Family and Community Medicine, Division of School-Based Programs. ${ }^{14}$

After the workshops, the educator developed an agenda of activities to present throughout the school year as part of a safety education curriculum. It included items such as students practising placing a doll in a child safety seat, special events during Grandparents' Day, and health fairs that included students wearing their VIP $\mathrm{T}$ shirts and the parents completion of a safety check-up sheet.

\section{(3) Law enforcement}

The Houston Police Department provided four officers to survey the target areas for two eight hour shifts a week. When an officer saw a motorist properly restrained, the driver was given a small prize/incentive package (positive encounter). This incentive package included (1) a drawing for a $\$ 500$ cash prize, (2) a chance to win a color TV, (3) gift certificates for local grocery stores and jewelry stores, and
(4) a VIP key chain. When a motorist-either driver or passenger-was caught improperly restrained, the driver received a traffic citation (negative encounter).

In Texas, children ages 2 and under are required to be restrained in a child safety seat; between 2 and 4 they must use a car seat or seat belt; and all persons in front seats are required to use seat belts. There is a $\$ 55$ fine and a $\$ 30$ court fee for any violation of the vehicle restraint law.

\section{(4) Private industry}

Corporate underwriting from 14 companies enhanced the VIP program by providing educational materials and VIP $T$ shirts for elementary students, and incentives for properly restrained motorists.

\section{(5) Government}

Government officials at the city, county, state, and national levels were enlisted to lead the effort to increase proper use of car seats and seat belts.

\section{(6) Media}

Print, radio, and television media informed the general public about the VIP program and the hazards of improper vehicle restraint.

\section{EVALUATION METHODS}

Evaluations of the effectiveness of the VIP program were conducted by independent observers from the Texas Department of Health. The data presented here reflect the first year's results. On two separate occasions observers recorded proper restraint use at two target area schools and at two comparison schools. The observational methods were developed by the Texas Transportation Institute, part of Texas A\&M University. Observers were masked as to which schools were in the target area and which were comparison. The first observation occurred in September 1996 (pre-intervention) and the second was nine months later (postintervention). They were conducted in like weather conditions at the same time of day. Observers recorded the number and type of vehicles and the number of properly restrained and unrestrained drivers, front and rear seat passengers, children in cargo areas, and children in car seats. Proper restraint was defined as using shoulder and lap belts in the front seat, using a rear facing car seat for infants or forward facing seat for toddlers, and all other back seat passengers using a lap belt. Motorists were unaware their restraint use was being assessed.

\section{STATISTICAL METHODS}

Sociodemographic differences in ethnicity and the frequency of free or reduced cost lunches between the target and control schools (used elsewhere ${ }^{15}$ as a proxy for measuring socioeconomic status), were assessed by a standard binomial proportion test.

A standard proportion test was also used to evaluate the statistical significance of differences between pre-intervention and post-intervention observations of restraint use, as well as the $95 \%$ 
Table 1 Demographic characteristics of each observed school

\begin{tabular}{|c|c|c|c|c|c|c|c|}
\hline \multirow[b]{2}{*}{ Characteristics } & \multicolumn{3}{|c|}{ Intervention schools } & \multicolumn{3}{|c|}{ Comparison schools } & \multirow{2}{*}{$\begin{array}{l}\text { Houston school district } \\
\text { (all elementary) } \\
(n=115 \text { 847) }\end{array}$} \\
\hline & $1(n=526)$ & $2(n=543)$ & $\begin{array}{l}\text { Both } \\
(n=1069)\end{array}$ & $1(n=855)$ & $2(n=547)$ & $\begin{array}{l}\text { Both } \\
(n=1402)\end{array}$ & \\
\hline African-American ${ }^{\star}$ & 82 & 90 & 86 & 2 & 76 & 39 & 34 \\
\hline Asian & 0 & 1 & 0.5 & 0 & 4 & 2 & 2 \\
\hline Hispanic ${ }^{\star}$ & 18 & 7 & 12.5 & 93 & 20 & 56.5 & 54 \\
\hline White` & 0 & 2 & 1 & 4 & 0 & 2 & 10 \\
\hline Free/reduced lunch ${ }^{\star}$ & 92 & 63 & 77.5 & 97 & 97 & 97 & 81 \\
\hline
\end{tabular}

^Intervention schools combined and comparison schools combined are significantly different from one another $(p<0.05)$.

confidence interval (CI). ${ }^{16}$ The data were analyzed further to identify which occupants may have accounted for the change in use.

\section{Results}

CHARACTERISTICS OF THE SCHOOLS

As shown in table 1, both intervention schools were predominantly African-American (82\%, $90 \%$ ); one control school was predominantly Hispanic (93\%) and the other predominantly African-American (76\%). ${ }^{17}$ When the intervention schools were combined and the control schools were combined, the control schools were predominantly Hispanic $(56 \%)$ and the comparison schools were predominantly African-American (86\%). Ninety seven per cent of both control schools received free or reduced cost lunches, compared with $92 \%$ and $63 \%$ of students at intervention schools. Taken together, the intervention schools had fewer children getting free or reduced lunches compared with the control schools (that is, were of higher socioeconomic status).

RESTRAINT USE

Observed restraint use before the intervention was $33 \%$ and $43 \%$ for the two intervention schools and $31 \%$ and $37 \%$ for the comparison schools. After the intervention, the intervention schools' restraint use increased to $47 \%$ and $57 \%$, while the two comparison schools remained the same (fig 1). Although one comparison school actually decreased in per cent restraint use, there was no statistically significant difference pre-intervention and postintervention in either school individually or after combining their results.

These findings indicate that, when further categorizing the occupants by seating position, intervention school 2 was the only one to demonstrate an increase from pre-program to postprogram in rear seat passenger vehicle restraint use $(n=46$ and $35 ; z=3.42$; CI 0.13 to 0.48 ; $\mathrm{p}<0.0007)$. There was no increase in the other two categories-drivers or front seat passengers - at any of the other three schools. However, it is important to note that intervention school 2, a magnet school for gifted and talented children, started out with a restraint use rate higher than intervention school 1 $(43 \%$ v 33\%; $\mathrm{p}=0.04)$.

Another interesting finding is that the mean number of occupants per car was less for the two intervention schools combined than for the two comparison schools, both at baseline $(2.10$ $v 2.96$ occupants per car; $\mathrm{z}=4.47 ; \mathrm{p}<0.0001$ ) and after the intervention (2.03 v 3.00 occupants per car; $\mathrm{z}=4.17 ; \mathrm{p}<0.0001$ ).

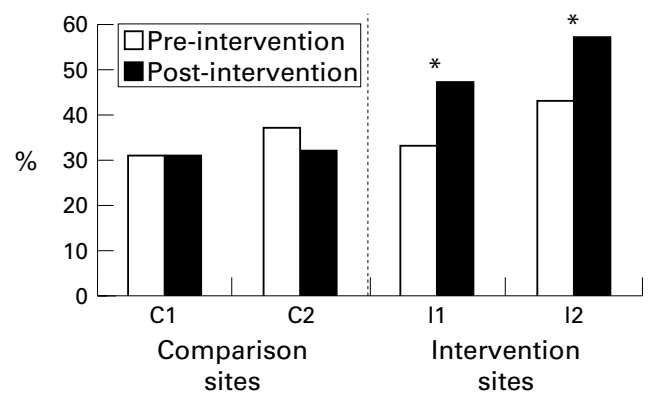

Figure 1 Motorists' restraint use $\left({ }^{*} p<0.05\right)$.

\section{Discussion}

An adaptation of the Click It or Ticket program implemented in small, homogeneous communities in North Carolina was found to be feasible in the contrasting environment of an impoverished neighborhood in the large, multiethnic community of Houston, Texas. The VIP program investigators were able to adapt North Carolina's program to address its own community's needs, social norms, and characteristics. ${ }^{12}$ In so doing, the VIP program effectively implemented its own safety education and awareness program, with economic incentives, to increase vehicle restraint use in the target area.

Studies sponsored by the NHTSA indicate that multifaceted community education programs are required to improve restraint use. ${ }^{18}$ As discussed by Altman, it is important to gain broad based support from a cross section of community constituencies to sustain an intervention. ${ }^{19} \mathrm{~A}$ researcher-community partnership can foster many positive outcomes, including the exchange of knowledge and resources, leading to more effective, sustainable community programs.

Teaching school age children the importance of vehicle restraint use increased restraint use both by the children and their parents, ${ }^{20}$ although Hazinski et al found this to be true only in low income schools with good program implementation. ${ }^{15}$ Low income schools with poor program implementation and high income schools did not significantly increase their restraint use. In our study, one might speculate that driver restraint use did not improve whereas passengers' combined use increased because the intervention was more concentrated in the school system than in the target area as a whole.

Wallack and Dorfman found that media advocacy can provide community groups with an independent voice to lend visibility, legitimacy, and credibility to their concerns. ${ }^{21}$ In our study, media coverage and safety education in the health care environment were not limited to 
the target areas. It is apparent, however, that these two strategies alone are not sufficient to increase restraint use to the extent desired.

Before our intervention, the intervention schools' restraint use was $33 \%$ and $43 \%$ and the two comparison schools' use was $31 \%$ and $37 \%$. This is a much lower rate than was found by the Texas Transportation Institute, who observed a $62 \%$ use rate in 14 Texas cities, with $8 \%$ incorrectly restrained. ${ }^{22}$ In Houston, they observed $54 \%$ restrained children at shopping centers (6\% incorrectly restrained) and $61 \%$ children restrained at day care centers $(11 \%$ incorrectly).

In the VIP program one of the intervention school's socioeconomic status, measured by the frequency of students on reduced cost or free lunches, was higher than the other $(p<0.0001)$. Higher socioeconomic status may be associated with this school's higher vehicle restraint use at the pre-intervention and post-intervention observations. Parents whose children are most at risk, that is, poor, undereducated, ${ }^{23}{ }^{24}$ are least likely to use safety precautions. Even middle class parents have neither a sense that their children are at risk for injury nor believe that parents should assume responsibility for teaching their children safe behavior. $^{25}$

The average number of occupants was significantly higher in the comparison schools. This may explain in part why restraint use differed both at baseline and after intervention between the intervention and comparison groups. Hazinski and colleagues observed that children were less likely to wear restraints when transported in large numbers, for example, in vans. ${ }^{15}$ According to NHTSA's 1996 Occupant Protection Use Survey, belt use was $66 \%$ in passenger cars but only $54 \%$ in vans, pick-ups, and utility vehicles. ${ }^{11}$ This potentially confounding variable, average number of occupants per vehicle, did not change in any of the schools and may have been controlled for by observing the schools at the same time of day and in like conditions.

\section{LIMITATIONS}

(1) Some of the same occupants may have been observed in the pre-observations and postobservations. Thus, the assumption of independence, which should exist when using a standard proportion test, does not strictly hold. ${ }^{15}$ (2) Observations of restraint use at the elementary school were limited to a "snapshot". For better representation of restraint use, the observations should have been expanded. (3) An evaluation of interobserver reliability would have been useful. However, reliability of these types of observations is typically high. ${ }^{26}{ }^{27}$ (4) There was potential contamination of the comparison sites by motorists who received the safety education at a target site, but who resided in a comparison site. However, this should have made it more difficult to detect a difference between the comparison and intervention schools. (5) There were also demographic differences between the schools. However, there was no significant difference in restraint use at baseline and follow up between the comparison schools with different ethnicity. This suggests that differences in ethnicity did not explain the increased use in the intervention group. There was a significant difference between the intervention schools with different socioeconomic status, consistent with many other studies showing an association between higher socioeconomic status and safety behaviors. Both the lower and relatively higher socioeconomic status intervention schools increased with the program, however, suggesting that the intervention was effective regardless of the socioeconomic status. (6) Finally, it is not known how long the effects will last. Goodman and Steckler state that a commitment to the concept and the presence of (a) program champion(s) is essential to sustaining an intervention. VIP appears to meet both requirements. ${ }^{28}$

\section{Implications for prevention}

Programs such as VIP, employing several strategies to increase vehicle restraint use and with sufficient flexibility to fit into diverse or indigent communities, appear to be an effective way to improve restraint use. It remains to be seen if the program can be successfully expanded to other high risk target communities. Additional work needs to be done to improve the program because the restraint use rate achieved is much less than that reported in countries with well enforced legislation.

The VIP program is funded through a partnership of Harris County Hospital District Foundation and Baylor College of Medicine.

1 Ross A, Baguley C, Hills B, et al. Towards safer roads in developing countries: a guide for planners and engineers. Crowthorne, UK: Transport and Road Research Laboratory, 1991.

2 National Committee for Injury Prevention and Control. Injury prevention: meeting the challenge. Am 7 Prev Med Injury prevention:

3 US Department of Transportation. Crash outcome data evaluation system (CODES) project safety belt and helmet evaluation system (CODES) project safety belt and helmet analyses. Research note, revised. Washington, DC: National Center for Statistics and Analysis, National H
fic Safety Administration, 15 February 1996.

fic Safety Administration, 15 February 1996.
4 Shanks NJ, Ansari M, Al-Kalai D. Road traffic accidents in Saudi Arabia. Public Health 1994;108:27-34.

5 Vaage T. Safety belt usage laws in various countries. Effectiveness of safety belt use laws: a multinational examination. Washington, DC: US Department of Transportation, National Highway Traffic Safety Administration, 1986 (publication No DOT-HS-807-018).

6 MacKay $M$. Seat belts and risk compensation. BMf 1985;291:757.

7 Parliamentary Advisory Council for Transport Safety. Department of Transport. London: HMSO, 1992.

8 Centers for Disease Control. Driver safety-belt useCenters for Disease Control. Driver safety-belt use-
Budapest, Hungary, 1993. MMWR Morb Mortal Wkly Rep Budapest, Hungary, 1993. MMWR
(December 10) 1993;42:939-41.

9 Baijal E, Carter H, Davie A. Car occupant restraint use in Fife: an observational study. Public Health 1993;107: $31-5$

10 US Department of Transportation. Occupant protection. Traffic safety facts. Washington, DC: National Center for Statistics and Analysis, National Highway Traffic Safety Administration, 1997.

11 US Department of Transportation. National occupant protection use survey -1996: controlled intersection study. Research note. Washington, DC: National Center for Statistics and Analysis, National Highway Traffic Safety Administration, 1997.

12 Campbell BJ, Hunter WW, Gemming MG, et al. The use of economic incentives and public education to increase seat belt use in a community. Chapel Hill: University of North Carolina, in a community. Chapel Hill: University

13 City of Houston, Planning and Development Department. 1994 Census tract data book. Houston: City of Houston, Planning and Development Department, 1995. 
14 Baylor College of Medicine. BrainLink: adventures in health and science education. Available from: htp://wwwand science education. Available from: http://w
sbp.bcm.tmc.edu/BrainLink/index.html. (2/27/98.)

15 Hazinski MF, Eddy VA, Morris JA Jr. Children's traffic safety program: influence of early elementary school safety education on family seat belt use. F Trauma 1995;39:10638.

16 Remington RD, Schork MA. Statistics with applications to the biological and health sciences. 2nd Ed. Englewood Cliffs, NJ Prentice-Hall, 1985.

17 Houston Independent School District. District \& school profiles 1996-1997. Houston: Houston Independent School District, 1997.

18 Gurin DB. Strategies to increase the use of safety belts by youngsters. Research note. Washington, DC: US Department of Transportation, National Highway Traffic Safety Administration, Office of Driver and Pedestrian Research, April 1990.

19 Altman DG. Sustaining interventions in community systems: on the relationship between researchers and comsystems: on the relationship between resea
munities. Health Psychol 1995;14:526-36.

20 Geller ES. A behavioral science approach to transportation safety. Bull N Y Acad Med 1988;64:632.
21 Wallack L, Dorfman L. Media advocacy: a strategy for advancing policy and promoting health. Health Educ $Q$ 1996;23:293-317.

22 Womack KN. 1994 survey of child restraint use in fourteen Texas cities. Texas Transportation Institute, Texax A\&M University System. September 1994 .

23 O'Shea JS. Childhood accident prevention strategies. Forensic Science Int 1986;30:99-111.

24 Pless IB, Verreault R, Tenina S. A case-control study of pedestrian and bicyclist injuries in childhood. Am f Public Health 1989;79:995-8.

25 Peterson L, Farmer J, Kashani JH. Parental injury prevention endeavors: a function of health beliefs? Health Psychol 1990;9:177-91.

26 Roberts MC, Fanurik D. Rewarding elementary schoolchildren for their use of safety belts. Health Psychol 1986;5: 185-96.

27 Roberts MC, Fanurik D, Wilson DR A community program to reward children's use of seat belts. Am 7 Comprogram to reward children's use of

28 Goodman RM, Steckler A. A model for the institutionalization of health promotion programs. Family and Community Health 1989;11:63-78.

\section{A preventable tragedy}

A small town in Quebec is mourning the death of seven children, ages $2-5$, who were killed when the driver of a minivan in which they were being transported lost control and collided with another vehicle. Designed to hold seven passengers, the van was carrying 10 children. A child of the driver, the operator of the daycare center attended by the victims, was among those killed. Although children of this age are required to be in car seats, only one such restraint was found. None of the media coverage of this avoidable tragedy has commented on the likelihood that the local police had ignored this gross violation of the highway code. It seems certain this was not the first time that children from this center, or others in the community, were being transported in this hazardous manner. It is also noteworthy that Quebec has no regulations governing the transport of children by daycare operators. The fine for driving with a child who is not properly restrained is not more than $\$ 100$. I blame the police and the province for their indifference to this issue. I also blame myself for failing to get the message about car safety out as clearly and forcefully as I should have. (BP)

\section{Gun childproofing breakthrough in the US}

In a breakthrough negotiated by the Clinton administration in the face of National Rifle Association opposition, the gun manufacturers, Smith and Wesson, announced in March that they would try to make handguns childproof. The plan is include a lock with every handgun it sells within 60 days, to build internal locks into all guns within two years, and to incorporate "smart gun" technology within three years. Although it falls far short of the total ban most safety groups wish, it is a giant step in the right direction. (BP)

Without comment: quotes from opponents of the childproofing agreement:

The company's [Smith and Wesson] executives, "violated a trust with their consumers and with the entire domestic firearms industry ...." (National Shooting Sports Foundation)

"back-door blackmail" .. (National Rifle Association)

"I don't think it deals with the problem, which is sociological" (US Citizens Committee for the Right to Keep and Bear Arms) 